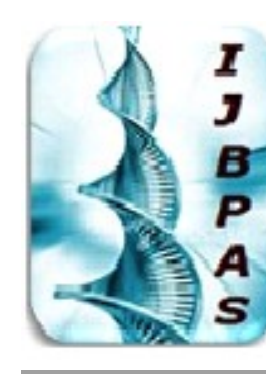

International Journal of Biology, Pharmacy and Allied Seiences (IJBPAS)

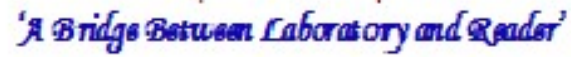

Www.iibpas.com

\title{
DETERMINATION OF OSTEOPONTIN, OSTEONECTIN AND BONE SIALOPROTEIN AND THEIR INTERPLAY IN THE PROGRESSION OF CA PROSTATE
}

\section{MUBASHER AHMAD ${ }^{2}$, HINA BASHIR ${ }^{3}$, HASSAN JAMIL ${ }^{3}$, SULAYMAN WAQUAR ${ }^{1}$, QURBAN ALI ${ }^{1}$, ARIF MALIK ${ }^{1^{*}}$}

1: Institute of Molecular Biology and Biotechnology, The University of Lahore-Pakistan

2: Department of Biochemistry, Punjab Medical College University, Lahore-Pakistan

3: Sharif Medical and Dental College, Lahore-Pakistan

*Corresponding author: Arif Malik: Email: arifuaf@yahoo.com; Cell: 0321-8448196

Received 15 ${ }^{\text {th }}$ Dec. 2018; Revised $3^{\text {rd }}$ Jan. 2019; Accepted $28^{\text {th }}$ Jan. 2019; Available online $1^{\text {st }}$ May 2019

\section{https://doi.org/10.31032/IJBPAS/2019/8.5.4724}

\section{ABSTRACT}

Prostate cancer is the cancer of prostate gland which resides under the urinary bladder, and in anterior of the rectum and its size changes with the growing age. It develops quickly during the puberty and pumped by the increase in androgens. These hormones include testosterone and dihydrotestosterone (DHT). There were 50 healthy individuals included as control group and 50 diagnosed prostate cancer patients were taken as subjects. The blood sample was centrifuged within one hour and serum was separated. MDA, SOD, GSH, GR, CAT, was assessed by spectrophotometrically. WhereasIL-6, TNF- $\alpha$, OPG, sRANKL, Osteonectin, Osteopontin, Osteocalcin and bone Sialoprotein were measured by commercially available ELISA kits. Malondialdehyde (MDA) play a crucial role in the pathogenesis and progression of prostate cancer. The level of MDA was significantly $(\mathrm{p}=0.015)$ raised in prostate cancer patients $(3.66 \pm 0.42 \mu \mathrm{mol} / \mathrm{L})$ as compared to healthy control $(0.93 \pm 0.033 \mu \mathrm{mol} / \mathrm{L})$. Enzymatic and nonenzymatic antioxidants profile specifically include SOD, GSH, CAT and GR reflect destructive role of ROS in the development of prostate cancer. Decrease level of SOD $(0.46 \pm 0.061 \mathrm{U} / \mathrm{ml} \mathrm{Vs}$. $0.63 \pm 0.067 \mathrm{U} / \mathrm{ml}), \mathrm{GSH}(5.16 \pm 1.26 \mu \mathrm{mol} / \mathrm{L}$ Vs. $8.26 \pm 3.26 \mu \mathrm{mol} / \mathrm{L}), \mathrm{GR}(3.28 \pm 0.09 \mu \mathrm{mol} / \mathrm{L}$ Vs. 
$6.99 \pm 1.08 \mu \mathrm{mol} / \mathrm{L})$ and CAT $(4.08 \pm 1.33 \mathrm{U} / \mathrm{L}$ Vs. $6.45 \pm 1.88 \mathrm{U} / \mathrm{L})$ were observed in prostate cancer patients as compared to healthy individuals. The level of proinflammatory cytokines IL- 6 and TNF- $\alpha$ differed significantly increased in disease group $(15.66 \pm 4.19 \mathrm{pg} / \mathrm{ml}$ and $31.26 \pm 4.16$ $\mathrm{pg} / \mathrm{ml})$ as compared to controls $(6.22 \pm 2.08 \mathrm{pg} / \mathrm{mland} 20.18 \pm 3.29 \mathrm{pg} / \mathrm{ml})$. Increased levels of OPG, sRANKL, osteonectin, osteopontin, osteocalcin and bone sialoprotein were observed in prostate cancer patients $(489.26 \pm 16.33 \mathrm{ng} / \mathrm{ml}, 4.26 \pm 1.22 \mathrm{ng} / \mathrm{ml}, 209.92 \pm 4.16 \mathrm{ng} / \mathrm{ml}, 658.29 \pm 4.19$ $\mathrm{ng} / \mathrm{ml}, \quad 5.16 \pm 4.26 \mathrm{ng} / \mathrm{ml}$ and $286.26 \pm 6.35 \mathrm{ng} / \mathrm{ml}$ ) as compared to control individuals $(655.26 \pm 15.36 \mathrm{ng} / \mathrm{ml}, 1.74 \pm 0.156 \mathrm{ng} / \mathrm{ml}, 68.29 \pm 6.26 \mathrm{ng} / \mathrm{ml}, 423.29 \pm 12.56 \mathrm{ng} / \mathrm{ml}, 3.06 \pm 6.35$ $\mathrm{ng} / \mathrm{ml}$ and 155.26 $\pm 3.29 \mathrm{ng} / \mathrm{ml}$ ). Present study depicts that osteopontin, osteonectin and bone sialoprotein contribute in the progression of tumor in prostate cancer. Moreover, the expression of these variables varies between different types of bone metastasis. The expression of these bone proteins have strongly associated with osteoporotic phenotype in prostate cancer. Osteopontin, osteonectin and bone sialoprotein are the potential novel biomarkers and anticancer therapeutic target to manage tumor progression in prostate cancer.

\section{Keywords: Prostatecancer, Malondialdehyde, Interlukins-6, Tumor necrosis factor- $\alpha$, osteopontin, osteonectin, bone sialoprotein}

\section{INTRODUCTION}

Cancer the deadliest disease nowadays and out of all types of cancers, prostate cancer (PCa) is the second most commonly occurring cancer after skin cancer worldwide and it is the sixth leading cause of death in men [1]. It is mostly developed in the age over fifty and the rate of PCa in Pakistan is 5.3 per 1 lac persons per year [2]. Prostate cancer is the cancer of prostate gland which resides under the urinary bladder, and in anterior of the rectum and its size changes with the growing age. It develops quickly during the puberty and pumped by the increase in androgens. These hormones

include testosterone and dihydrotestosterone (DHT). The prostate is involved to produce fluid that protects sperm cells [3]. There are various kinds of cells on prostate gland but nearly every type of prostate cancer develops from cells of gland which is known as adenocarcinoma. Neuroendocrine tumors, small cell carcinomas, transitional cell carcinomas and sarcomas are included in other types of cancers [4]. There are some precancerous conditions of prostate which includes Prostatic intraepithelial neoplasia (PIN) and proliferative inflammatory atrophy (PIA). The former has two possibilities 
which includes low grade PIN in which morphology of prostatic cells appears nearly typical and High-grade PIN in which morphology of prostate cells appears abnormal. The PIA is not a cancer but a condition in which cells seems smaller than normal and also show some marks of inflammation in the affected area [5].

There are several risk factors involved in prostate cancer but this does not necessarily means that a person would develop cancer if he is having one of the risk factors. These risk factors involve age in which prostate cancer may develop after the age of 40 and rises swiftly when the age crosses 50. About 6 in 10 cases are found in men who are above 65 [6]. The reasons for ethical differences are not clear but still it has been reported that this cancer is most frequent in Caribbean men and in AmericanAfrican men. It occurs less frequently in Asian men and in Hispanic/Latinos men as compared to nonhispanic whites. It has also been reported that prostate cancer seems to run in families. The genetic factors have also significantly role in the progression of prostate cancer. It has been observed that males are at higher risk if they have one or more relatives with the history of prostate cancer [7]. Genetic factors involves GSTP1 and NK3.1 gene silencing and PTEN gene silencing which increases the risk of prostate cancer [8]. The relation of diet with this cancer is still not very clear but some observations linked its relation like some men who eat high-fat dairy products and red meat and also eat fewer fruits and vegetables are seen to be at higher risk of developing prostate cancer [9]. Although prostate cancer is the glandular cancer but it can also invade other organs like rectum, bones, bladder, lymph nodes and lower ureters. The course of bone is believed to be through vein. Urinary function is directly affected when changes in prostate gland occurs because the prostate gland surrounds the prostatic urethra. It is also involved in sexual dysfunction which could lead to erection problems or painful ejaculations [10]. Prostate cancer is metastatic and can cause additional symptoms in which the commonest is the bone pain particularly in vertebrae region, pelvis and ribs area. If the prostate cancer invades the spine hen it can also compress the spinal cord which could cause tingling, weakness in leg and fecal and urinary incontinence [11].

Prostate gland is a type of organ that accumulates zinc and produces citrate. ZIP1 protein is accountable for the vigorous transportation of zinc into the prostate cells. The procedure of zinc gathering, 
modification of digestion system, and citrate creation is energy inefficient and the prostate cells have to sacrifice huge amounts of energy in the form of ATP for this purpose. Prostate cancer cells are normally lacking in zinc which lets them to reserve energy by not producing citrate so that they can utilize this large quantity of energy for growth and to spread. It is assumed that by the silencing of gene SLC39A1, the absence of zinc occurs. There are some genes that suppress the tumor and are believed to contribute in PCa. These include PTEN and KAI1.It is reported that up to 70 percent affected males with PCa do not have one counterpart of PTEN gene when they are diagnosed. A transcription factor RUNX2 averts cancer cells from going through apoptotic process which contributes in the progress of this cancer [12]. There are several ways of diagnosing prostate cancer but the most accurate is by taking biopsy in which small pieces of prostate are removed so that they could be examined using a microscope. Other methods include cystoscopy, Digital Rectal Examination (DRE), trans rectal ultrasonography, ultrasound and MRI [13]. After taking a biopsy, the specimen is observed using a microscope to check either the tumor cells are present or not and to further assess the microscopic characteristics of any cancer if found. This is done through Gleason score in which the cancer stage is determined by looking at the morphology of cancer cells. The more deformed cells will be at the least stage. Prostate specific antigen is overexpressed in prostate cancer tissues. It is a transmembrane carboxypeptidase and displays folate hydrolase activity which is associated with high Gleason score [14]. There has been evidence which supports that prostate cancer could be prevented by taking vegetarian diet. It could also be prevented by intake of foods which contains lycopenes and selenium. Foods that are rich in soy, beans, cruciferous vegetables and other legumes may also be associated with a decreased rate of prostate cancer. Physical activity is also thought to be associated with it. Men who do regular exercise are at lower risk as compared to men who does not do regular exercise [15]. Oxidative stress is considered to be the most noticeable characteristic of various chronic and acute diseases which includes cancer, lung disease, neurodegenerative disease, cardiovascular disease and the process of aging. It is categorized by difference between an increased level of free radicals and antioxidant defenses. Free radicals are mostly derived from oxygen. Antioxidants are composed of both small molecular weights 
antioxidants which includes glutathione and also composed of antioxidant enzymes which includes superoxide dismutase. There are two sources of free radicals' production. One is the endogenous source like mitochondria; oxidative burst during activation of phagocytes. Second is the exogenous source which includes environmental toxins and cigarette smoke. Free radicals cause direct damage to vital biomolecules like DNA, lipids and proteins. These free radicals include ROS and RNS [16]. Lipids are the chief goal of this attack which is persuades lipid peroxidation. It is a self-progressing phenomenon which is stopped by antioxidants.

\section{MATERIALS AND METHODS}

The present study was designed to investigate the role of osteopontin, osteonectin, bone sialoprotein andantioxidants in the development of prostate cancer. All the selected patients were screened at Inmol Hospital Lahore. Fifty male patients in the age group of 50-75 years were eligible for inclusion in the study. Informed consent was obtained before being included in this study. Twenty clinically apparently healthy individuals were included as controls. The experimental protocol was approved by the Research Ethical Committee of The Institute of molecular biology and biotechnology (IMBBP), The University of Lahore. Five $\mathrm{ml}$ of venous blood sample were taken from the anticubital vein of each participant. The sample bottles were centrifuged within one hour of collection, after which the serum were separated and stored at $-70^{\circ} \mathrm{C}$ until assayed.

\section{INCLUSION AND EXCLUSION CRITERIA}

Patients clinically diagnosed with prostate cancer were included in this study. The range of age group was 50-75 years. Random samples were collected with different stage of cancer.The subjects with the history of taking drugs (including alcohol and cigarette), pre-diagnosis medications (e.g. antiparkinsonian/antipsychotic), were excluded from this study. None of the controls were on any medication, history of chronic infections, malnutrition syndrome, depression, psychosis or metabolic dysfunction (Such as diabetes mellitus, liver diseases, cancer) that could interfere with their oxidative metabolites and thyroid hormone status.

\section{BIOCHEMICAL ASSAY}

Lipid peroxidation in blood samples was estimated calorimetrically by measuring Thiobarbituric acid reactive substances (TBARS) by the method of Ohkawa [17]. Superoxide dismutase (SOD) activity was 
determined by the method of Kakkar [18].Levels of glutathione, glutathione reductase and catalase were estimated according to the method of Moron[19], David and Richard [20]and Aebi [21].Levels of IL-6, TNF- $\alpha$, Osteoprotegrin (OPG), Osteonectin, Osteocalcin, Osteopontin,sRANKL and Bone Sialoprotein were also measured using commercially available ELISA kits (Bio-Vendor) by following their corresponding protocols.

\section{STATISTICAL ANALYSIS}

The statistical analysis was performed by SPSS statistics 17.0. The results of all biological variables were analyzed by independent sample t-test. One way ANOVA is used to measure the P-value.

\section{RESULTS}

DEMOGRAPHIC

AND

HEMATOLOGICAL PROFILE IN PROSTATE CANCER PATIENTS

Table 1 and 2 represent the demographic profile of prostate cancer patients show the mean age and weight of the patients was $61.35 \pm 6.66 \mathrm{Yrs}$ and $83.26 \pm 4.16 \mathrm{~kg}$ as compared to control subjects $65.26 \pm 5.21$ Yrs and $81.65 \pm 8.29 \mathrm{~kg}$. The systolic and diastolic blood pressure of prostate cancer patients was $127.36 \pm 3.29 \mathrm{mmHg}$ and $83.23 \pm 5.18$ $\mathrm{mmHg}$ as compared to control $122.41 \pm 5.16$ $\mathrm{mmHg}$ and $81.26 \pm 2.33 \mathrm{mmHg}$. BMI of prostate cancer patients was $23.26 \pm 1.08$ $\mathrm{kg} / \mathrm{m}^{2}$ as compared to healthy subject $22.27 \pm 1.09 \mathrm{~kg} / \mathrm{m}^{2}$. Hematological profile of prostate patients as compared to control individuals includes RBCs, WBCs, Hb, BUN and creatinine. There was significant difference between the values of prostate groups and control group. The mean value of RBCs and $\mathrm{Hb}$ was significantly decreased $\left(3.09 \pm 0.56\right.$ million $/ \mathrm{mm}^{3}$ and $\left.13.29 \pm 1.4 \mathrm{~g} / \mathrm{dl}\right)$ in prostate cancer patients as compared to controls $\quad\left(4.99 \pm 1.05 \quad\right.$ million $/ \mathrm{mm}^{3}$ and $14.29 \pm 3.09 \mathrm{~g} / \mathrm{dl})$. On the other hand, the mean value of WBCs was significantly increased $\left(8.99 \pm 2.09\right.$ million $\left./ \mathrm{mm}^{3}\right)$ in prostate cancer patients versus control group $\left(7.66 \pm 1.56 \mathrm{million} / \mathrm{mm}^{3}\right)$. Highly significant increased levels of BUN and creatinine $(18.26 \pm 2.08 \mathrm{mg} / \mathrm{dl}$ Vs. $15.89 \pm 2.08 \mathrm{mg} / \mathrm{dl}$ and $2.26 \pm 0.066 \mathrm{mg} / \mathrm{dl}$ Vs. $0.89 \pm 0.021 \mathrm{mg} / \mathrm{dl}$ ) were observed in prostate cancer patients as compared to control individuals.

PROFILE OF STRESS BIOCHEMICAL MARKERS IN THE PATINETS

\section{HAVING PROSTATE CANCER}

Table 3 shows that themalondialdehyde (MDA) play a crucial role in the pathogenesis and progression of prostate cancer. The levelof MDA was significantly $(p=0.015)$ raised in prostate cancer patients (3.66 $\pm 0.42 \mu \mathrm{mol} / \mathrm{L})$ as compared to healthy 
control $(0.93 \pm 0.033 \mu \mathrm{mol} / \mathrm{L})$.Enzymatic and non-enzymatic antioxidants profile specifically include SOD, GSH, CAT and GR reflect destructive role of ROS in the development of prostate cancer. Decrease level of SOD $(0.46 \pm 0.061 \mathrm{U} / \mathrm{ml}$ Vs. $0.63 \pm 0.067 \mathrm{U} / \mathrm{ml})$, GSH $(5.16 \pm 1.26 \mu \mathrm{mol} / \mathrm{L}$ Vs. $8.26 \pm 3.26 \mu \mathrm{mol} / \mathrm{L}), \quad$ GR $(3.28 \pm 0.09$ $\mu \mathrm{mol} / \mathrm{L}$ Vs. $6.99 \pm 1.08 \mu \mathrm{mol} / \mathrm{L})$ and CAT $(4.08 \pm 1.33 \mathrm{U} / \mathrm{L}$ Vs. $6.45 \pm 1.88 \mathrm{U} / \mathrm{L})$ were observed in prostate cancer patients as compared to healthy individuals. The level of proinflammatory cytokines IL- 6 and TNF- $\alpha$ differed significantly increased in disease group $(15.66 \pm 4.19 \mathrm{pg} / \mathrm{ml}$ and $31.26 \pm 4.16$ $\mathrm{pg} / \mathrm{ml})$ as compared to controls $(6.22 \pm 2.08$ $\mathrm{pg} / \mathrm{ml}$ and $20.18 \pm 3.29 \mathrm{pg} / \mathrm{ml}$ ). he level of OPG (pg/ml) was decreased significantly $(p=0.033)$ in patients as compared to healthy individuals. Increased levels of OPG, sRANKL, osteonectin, osteopontin, osteocalcin and bone sialoprotein were observed in prostate cancer patients (489.26 $\pm 16.33 \mathrm{ng} / \mathrm{ml}, \quad 4.26 \pm 1.22 \mathrm{ng} / \mathrm{ml}$, $209.92 \pm 4.16 \mathrm{ng} / \mathrm{ml}, \quad 658.29 \pm 4.19 \mathrm{ng} / \mathrm{ml}$, $5.16 \pm 4.26 \mathrm{ng} / \mathrm{ml}$ and $286.26 \pm 6.35 \mathrm{ng} / \mathrm{ml}$ ) as compared to control individuals $(655.26 \pm 15.36 \mathrm{ng} / \mathrm{ml}, \quad 1.74 \pm 0.156 \mathrm{ng} / \mathrm{ml}$, $68.29 \pm 6.26 \mathrm{ng} / \mathrm{ml}, \quad 423.29 \pm 12.56 \mathrm{ng} / \mathrm{ml}$, $3.06 \pm 6.35 \mathrm{ng} / \mathrm{ml}$ and $155.26 \pm 3.29 \mathrm{ng} / \mathrm{ml}$ ).

Table 1: Demographic/Physical Characteristic of Prostate Patients vs. Control

\begin{tabular}{|c|c|c|c|}
\hline CHARACTERISTICS & CONTROL $(\mathrm{n}=\mathbf{5 0})$ & SUBJECTS $(\mathrm{n}=\mathbf{5 0})$ & P $\leq$ 0.05 \\
\hline Age (Yrs) & $\mathbf{6 5 . 2 6} \pm 5.21$ & $\mathbf{6 1 . 3 5} \pm 6.66$ & $\mathbf{0 . 2 6 1}$ \\
\hline Weight (kg) & $\mathbf{8 1 . 6 5} \pm \mathbf{8 . 2 9}$ & $\mathbf{8 3 . 2 6} \pm 4.16$ & $\mathbf{0 . 5 1 2}$ \\
\hline SBP $(\mathrm{mmHg})$ & $\mathbf{1 2 2 . 4 1} \pm 5.16$ & $\mathbf{1 2 7 . 3 6} \pm 3.29$ & $\mathbf{0 . 6 2 1}$ \\
\hline DBP $(\mathrm{mmHg})$ & $\mathbf{8 1 . 2 6} \pm 2.33$ & $\mathbf{8 3 . 2 3} \pm 5.18$ & $\mathbf{0 . 1 9 2}$ \\
\hline BMI $\left(\mathrm{kg} / \mathrm{m}^{2}\right)$ & $\mathbf{2 2 . 2 7} \pm 1.09$ & $\mathbf{2 3 . 2 6} \pm 1.08$ & $\mathbf{0 . 1 5 6}$ \\
\hline
\end{tabular}

Table 2: Heamatological Profiles of Prostate Patients vs. Control

\begin{tabular}{|c|c|c|c|}
\hline VARIABLES & CONTROL $(n=50)$ & SUBJECTS $(n=50)$ & $P \leq 0.05$ \\
\hline RBCs (million/mm³) & $4.99 \pm 1.05$ & $3.09 \pm 0.56$ & 0.062 \\
\hline WBCs (Million/mm³ & $7.66 \pm 1.56$ & $8.99 \pm 2.09$ & 0.056 \\
\hline $\mathrm{Hb}(\mathrm{g} / \mathrm{dl})$ & $14.29 \pm 3.09$ & $13.29 \pm 1.4$ & 0.085 \\
\hline BUN (mg/dl) & $15.89 \pm 2.08$ & $18.26 \pm 2.08$ & 0.042 \\
\hline Creatinine (mg/dl) & $0.89 \pm 0.021$ & $2.26 \pm 0.066$ & 0.009 \\
\hline
\end{tabular}

Table 3: Stress Biochemical Markers of Prostate Patients Vs. Control

\begin{tabular}{|c|c|c|c|}
\hline VARIABLES & CONTROL $(\mathrm{n}=50)$ & SUBJECTS $(n=50)$ & $P \leq 0.05$ \\
\hline MDA $(\mu \mathrm{mol} / \mathrm{L})$ & $0.93 \pm 0.033$ & $3.66 \pm 0.42$ & 0.015 \\
\hline SOD $(\mathbf{U} / \mathbf{m l})$ & $0.63 \pm 0.067$ & $0.46 \pm 0.061$ & 0.001 \\
\hline GSH $(\mu \mathrm{mol} / \mathrm{L})$ & $8.26 \pm 3.26$ & $5.16 \pm 1.26$ & 0.026 \\
\hline GRx $(\mu \mathrm{mol} / \mathrm{L})$ & $6.99 \pm 1.08$ & $3.28 \pm 0.09$ & 0.000 \\
\hline CAT (U/L) & $6.45 \pm 1.88$ & $4.08 \pm 1.33$ & $\mathbf{0 . 0 2 7}$ \\
\hline IL-6 (pg/ml) & $6.22 \pm 2.08$ & $15.66 \pm 4.19$ & 0.011 \\
\hline TNF- $\alpha(\mathrm{pg} / \mathrm{ml})$ & $20.18 \pm 3.29$ & $31.26 \pm 4.16$ & $\mathbf{0 . 0 3 2}$ \\
\hline Osteoprotegrin (OPG) (pg/ml) & $655.26 \pm 15.36$ & $489.26 \pm 16.33$ & $\mathbf{0 . 0 3 3}$ \\
\hline sRANKL (ng/dl) & $1.74 \pm 0.156$ & $4.26 \pm 1.22$ & 0.026 \\
\hline Prostatin acid phosphate (PAP)ng/ml & $0.17 \pm 0.077$ & $3.25 \pm 0.87$ & 0.017 \\
\hline Osteonectin $(\mathrm{ng} / \mathrm{ml})$ & $68.29 \pm 6.26$ & $209.92 \pm 4.16$ & 0.016 \\
\hline Osteopontin (ng/ml) & $423.29 \pm 12.56$ & $658.29 \pm 4.19$ & 0.023 \\
\hline Bone Sialoprotein (ng/ml) & $155.26 \pm 3.29$ & $286.26 \pm 6.35$ & 0.011 \\
\hline Osteocalcin (ng/ml) & $3.06 \pm 6.35$ & $5.16 \pm 4.26$ & 0.016 \\
\hline
\end{tabular}


Table 4: Pearson S' Correlation Cofficient OF Prognostic Variables of Male With Prostate Cancer

\begin{tabular}{|c|c|c|}
\hline e & $(\mathbf{r})$ & P-VALUE \\
\hline MDA Vs GSH & $\mathbf{- 0 . 5 1 2 ^ { * * }}$ & \\
\hline IL-6 Vs MDA & $\mathbf{0 . 4 5 4 ^ { * * }}$ & \\
\hline MDA Vs CAT & $\mathbf{- 0 . 6 3 * *}$ & \\
\hline MDA Vs SOD & $\mathbf{- 0 . 7 1 ^ { * * }}$ & \\
\hline
\end{tabular}

\section{DISCUSSION}

Although prostate cancer is the glandular cancer but it can also invade other organs like rectum, bones, bladder, lymph nodes and lower ureters. The course of bone is believed to be through vein. The main course of its metastasis is bone. There is another causative factor of cancer which is believed to be caused by an increase in oxidative stress [22]. Oxidative stress is an imbalance between the levels of oxidants and antioxidants. Usually oxidative stress is increased in cancer due to which the levels of antioxidants get affected. This oxidative stress leads towards various phenomenon like inflammation, lipid peroxidation which have deleterious effects on cells [23]. Oxidative stress is increased due to the generation of free radicals like reactive oxygen species and reactive nitrogen species [24]. Like all other cancers, oxidative stress is also increased in the prostate cancer due to which the levels of antioxidants like GSH, CAT, GSH-Px, SOD (Cu-SOD, Mn-SOD and Zn-SOD), GR, Vitamins $\mathrm{A}, \mathrm{E}$ and $\mathrm{C}$ get affected. Other inflammatory markers include Interlerkin-6 and TNF- $\alpha$. The oxidative markers are glutathione (GSH), catalase (CAT), glutathione reductase (GR), glutathione peroxidase (GSH-Px), Superoxide dismutase (SOD) which includes $\mathrm{Mn}-\mathrm{SOD}, \mathrm{Cu}-\mathrm{SOD}$ and Zn-SOD. When the levels of micronutrients like $\mathrm{Cu}, \mathrm{Mn}, \mathrm{Fe}$ and $\mathrm{Zn}$ are affected then the SOD levels get affected. Other antioxidants include vitamin like vitamin $\mathrm{A}, \mathrm{E}$ and $\mathrm{C}$. In this study each parameter is being analyzed and discussed. Glutathione (GSH) is the chief soluble antioxidant which is found abundantly in all cell compartments [25]. The ratio of GSH and GSSG is a key factor of oxidative stress. Theantioxidants detoxify $\mathrm{H}_{2} \mathrm{O}_{2}$ and lipid peroxides through the action of Glutathione peroxidase. GSH gives one of the electrons to hydrogen peroxide to reduce it into water and oxygen. In this study the levels of glutathione were decreased as the stage of the cancer is progressed in comparison to controls. The levels were lowest at stage III which indicates that as the stage progresses the oxidative stress is increased due to which the levels of glutathione decreases and along with this it showed a highly significant inverse correlation with MDA (GSH Vs 
MDA, $r=-0.512 * *)$ as shown in table 4 . This depicts that if the levels of GSH are decreased then the antioxidative activity would also decrease which would in turn increase the process of inflammation and hence the production of MDA. This indicates that all these antioxidants might act in coordination with each other to combat against oxidative stress. However, the present study contradicts with the findings of Maricnaet al., 2012 who reported a down fall in the levels of glutathione in PCa patients. Hydrogen peroxide which is generated through the activity of superoxide dismutases or by oxidases such as xanthin oxidase is diminished to $\mathrm{H}_{2} \mathrm{O}$ via the action of glutathione peroxidase and catalase [26]. Catalase occurs in the form of a tetramer which is made out of four indistinguishable monomers, every monomer holds a heme bunch at the dynamic site [27]. Degradation of the hydrogen peroxide is achieved through a change among the two adaptations of catalase-ferricatalase ( $\mathrm{Fe}$ attached to $\mathrm{H}_{2} \mathrm{O}$ ) and compound II (Fe attached to an $\mathrm{O}_{2}$ particle). The levels of catalase and glutathione reductase were higher in control group and lower in the prostate cancer patients who indicate that the levels got decreased due to the increase of oxidative stress and with the progression of disease the levels got even lower. This data was consistent with the findings Srivastava [28]who reported a decrease in the levels of catalase and GR in patients suffering from prostate cancer [28]. Glutathione reductase reduces GSSG into glutathioneby utilizingNAD $(\mathrm{P}) \mathrm{H}$ as the donor of electron. The levels were lowered in control group and were raised in the patients. At stage I and II the levels were raised which indicate that the antioxidant activity was at its peak to combat against oxidative stress then got decreased at stage III as the disease progressed [29]. This result was contradictory with the findings of Iynemet al., 2004 who reported a rise in the levels of GR in patients with prostate cancer.

Interleukin-6 is a pro-inflammatory cytokine and it acts in the cross talking between inflammatory cells and cells of prostate cancer and it also stimulates malignant processes, inducing angiogenesis and apoptosis [30]. Moreover, it has been reported that this cytokine increases propagation and operates as an endurance molecule for various cell lines of prostate tumor like LNCaP, PC3 and DU145 [31]. Tumor necrosis factor- $\alpha$ is another proinflammatory cytokine which is known to act as a key participant in many tumor's growth. It has been reported that serum containing high levels of TNF- $\alpha$ and 
interleukin- 6 are related with the advanced metastatic condition and the survival rate is also decreased in these patients. The levels of TNF- $\alpha$ were increased in prostate cancer patients as compared to healthy individuals which depicts that there is high survival rate of tumor cells with more proliferation and advance metastasis. The levels of IL-6 were also higher in prostate cancer patients which indicate more tumor growth and angiogenesis in the patients. The result of the present study shows that IL-6 significantly correlated with MDA (IL-6 Vs MDA, r=0.454**) in table 4. Interleukin-6 is recognized as a multi factorial cytokine which is the chief stimulator of the Janus kinases (JAK/Signal Transducer and Activator of Transcription (STAT3) signaling pathway. Along with JAK/STAT, IL-6 may phosphorylate Akt and mitogen activated protein kinases (MAPK). Various pathways can be activated in reaction to IL-6 in the cell at the same time. STAT3 is also phosphorylated by epidermal growth factor and has been considered as an oncogene in many cancers and its capability to cause malignant cellular transformations [32]. When IL-6 binds to its receptor the JAK2 and JAK3 on the receptor gets phosphorylated, due to this activation the STAT3 molecules are recruited towards the JAKs and gets phosphorylated. These phosphorylated STAT3 molecules forms a dimer. This dimeric complex will move towards the nucleus [33]. After entering the nucleus, it will bind to its specific DNA binding site and would activate its functions like proliferation, anti-apoptosis, differentiation, angiogenesis and inflammation [34].Eventually STAT3 activation leads to an increase in the inflammatory process, due to which cellular damage is increased and atrophy of the cells is also increased which leads to the conditions like PIA or PIN which eventually lead towards prostate cancer [35]. IL-6 has been linked with anti-apoptotic activity and it has been stated that IL-6 leads to the activation of phosphatidylinositol 3-kinase (PI3K) pathway.An extracellular survival signal activates a Receptor Tyrosine Kinase (RTK), that recruits and triggers PI 3-kinase. The PI 3-kinase produces PI(3,4,5)P3, which works as a docking site for two serine/threonine kinases having PH domains Akt and the phosphoinositol-dependent kinase PDK1 which are brought into close proximity at the plasma membrane [36]. The Akt gets phosphorylated on a serine by a third kinase (mostlymTOR), which modifies the conformation of the Akt so that it could be phosphorylated on a threonine by PDK1, which stimulates the Akt. The activated 
Aktgets dissociated from the plasma membrane and phosphorylates different target proteins, including the Bad protein. When unphosphorylated, Bad hold one or more apoptosis-inhibitory proteins in an inactive state. Once phosphorylated, Bad releases the inhibitory proteins, which could now block apoptosis and thus promote cell survival. As shown, once phosphorylated, Bad binds to a ubiquitous cytosolic protein called 14-3-3, which keeps Bad out of action [37]. Thus, IL-6 contributes to greater activity of Akt which was recurrently reported in prostate tumors. Along with this, TNF- $\alpha$ which is also an proinflammatory marker and is known to act as a key participant in many tumor's growth showed a significantly strong correlation with MDA which is an end product of lipid peroxidation. This shows if the levels of TNF- $\alpha$ are increased due to inflammation then the levels of SOD would fall which in turn decrease the antioxidant activity [38]. Malondialdehyde (MDA) is considered to be the most specific and reliable biomarker of lipid peroxidation. It is produced as a result of degradation of polyunsaturated lipids by ROS. It is a very reactive aldehyde and produces toxic stress in cells and make covalent protein adducts [39]. The levels of MDA were higher in patients suffering from prostate cancer in comparison to control group. This increased level depicts that the severity of lipid peroxidation is higher in patients as compared to controls. A highly significant inverse correlation was observed between MDA, catalase and SOD (MDA Vs catalase, $\mathrm{r}=-0.63^{* * *}, \quad$ MDA Vs SOD, $\mathrm{r}=-0.71^{* *}$ respectively) as shown in table 4 . This shows that if there is more production of MDA, then the levels of catalase and SOD are not enough to stop the attack of free radicals on lipid membrane due to which the process of lipid peroxidation intensifies.

\section{CONCLUSION}

The present study depicts that osteopontin, osteonectin and bone sialoprotein contribute in the progression of tumor in prostate cancer. Moreover, the expression of these variables varies between different types of bone metastasis. The expression of these bone proteins have strongly associated with osteoprotic phenotype in prostate cancer. Osteopontin is an important factor in osteoclast activation and differentiation of bone metabolism. Thereby, Osteopontin, osteonectin and bone sialoprotein are the potential novel biomarkers and anti-cancer therapeutic target to manage tumor progression in prostate cancer. 


\section{REFERENCES}

[1] Ahmet A, Z Arsova-Sarafinovska, A Sayal, A Eken, O Erdem, K Erten, YÖzgök and A Dimovski. Oxidative stress and antioxidant status in nonmetastatic prostate cancer and benign prostatic hyperplasia. Clin Biochem, (2006); 39(2): 176-179.

[2] Alexander DD, Mink PJ, Cushing CA, Sceurman B. A review and metaanalysis of prospective studies of red and processed meat intake and prostate cancer. Nutrition journal, (2010); 9:50.

[3] Aryal M, Pandeya A, Das BA, Lamsal M, Majhi S. Oxidative stress in patients with benign prostate hyperplasia. J Nepal Med Assoc, (2007);46: 103-106.

[4] Aydin A, Arsova SZ, Eken A, Erdem O, Erten K, Ozgök Y, DimovskiO. Oxidative stress and antioxidant status in non-metastatic prostate cancer and benign prostatic hyperplasia. Clin Biochem, (2006);39(2): 176-179.

[5] Basler JW, Piazza GA. Nonsteroidal anti-inflammatory drugs and cyclooxygenase-2 selective inhibitors for prostate cancer chemoprevention. J Urol, (2004);171:59-62.
[6] Bonfil RD, Fridman R, Mobashery S, Cher ML. Are matrix metalloproteinases relevant therapeutic targets for prostate cancer bone metastasis? Current Oncology, (2008); 15(4).

[7] Bostwick, David G, Eble R, N John Urological Surgical Pathology. St. Louis: Mosby. $\quad$ P, (2007); 468.

[8] Chen LH SR Lowry SR Cellular antioxidant defense system. Prog Clin Biol Res, (1989). 287:247-256.

[9] Cohen RJ, Shannon BA, McNealJE, Shannon T, Garrett KL. Propioni bacterium acnes associated with inflammation in radical prostatectomy specimens: a possible link to cancer evolution? J Urol, (2005); 173: 19691974.

[10] Cooney KA. Germ-line mutations of the macrophage scavenger receptor 1 gene: association with prostate cancer risk in African-American men. Cancer Res, (2003); 63:34863489.

[11] Coughlin SS, Hall IJ. A review of genetic polymorphisms and prostate cancer risk. Annals of Epidemiology, (2002); 12: 182-196. 
[12] Yilmaz MI, Saglam K, Sonmez A, Gok DE , Basal S. Antioxidant system activation in prostate cancer. Biol Trace Elem Res, (2004); 98(1): 13-19.

[13] Esra B, sahiner UM, sackesen $C$, Erzurum S, Kalaysi O. Oxidative stress and antioxidant defense. WAO journal, (2012);5:9-19.

[14] Culig Z, Puhr M. Interleukin-6: a multifunctional targetable cytokine in human prostate cancer. Mol Cell Endocrinol, (2012); 360(1-2):52-58.

[15] Daniel A, Saundra BM, Michael SC, Sam SC, David FP. Oxidative Stress Measured by Urine F2-Isoprostane Level Is Associated With Prostate Cancer. J Urol, (2011); 185(6): 2102-2107.

[16] Ghalia AA, Rabboh NA, Shalakani A, Seada L, Khalifa A. Estimation of glutathione S-transferase and its $\mathrm{Pi}$ isoenzyme in tumor tissues and sera of patients with ovarian cancer. Anticancer Res, (2000); 20: 12291235.

[17] Ohkawa H, Ohishi N, K Yagi K. Assay for lipid peroxides in animal tissues by thiobarbituric acid reaction. J Anal Biochem, (1979); 95: 351-358.
[18] Kakkar PB, P Das P, Viswanathan PN, A modified spectrophotometer assay of superoxide dismutase. Ind $\mathbf{J}$ Biochem Bio, (1984); 21: 130-132.

[19] Moron MS, DepierreJW, Mannervik B. Levels of glutathione reductase and glutathione S-transferase in rat lung and liver. Biochem Biophysic Act, 1979); 582: 67-68.

[20] David M, Richard JS. Methods of enzymatic analysis, (1983); 258265.

[21] Aebi H. Catalase in Bergmeyer HU Methods in Enzymatic Analysis: New York, Academic Press, (1974); 3: 276-286.

[22] Hood BL, Darfler MM, Guiel TG, Furusato B. Proteomic analysis of formalin fixed prostate cancer tissue. Mol Cell Proteomics,(2005).

[23] Dillner J, Knekt P, Boman J, Lehtinen M, GeijersstamV.Seroepidemiological association between human-papillomavirus infection and risk of prostate cancer. Int J Cancer, (1998); 75:564-567.

[24] Eichholzer M, Stahelin HB, LudinE, Bernasconi F. Smoking, plasma vitamins $\mathrm{C}, \mathrm{E}$, retinol, and carotene, and fatal prostate cancer: seventeenyear follow-up of the prospective 
Basel study. Prostate, (1999); 38: 189-198.

[25] Farmer EE, Davoine C.Reactive electrophile species.CurrOpin Plant Biol, (2007); 10(4): 380-386.

[26] Figueiredo JC, GrauMV, Haile RW, Sandler RS, RW Summers. Folic Acid and Risk of Prostate Cancer: Results from a Randomized Clinical Trial. J. Natl. Cancer Inst, (2009); $101(6): 432-5$

[27] Flemming N, M Bo Borg, BN Jesper, RA Helle and G Philippe (1997). Plasma malondialdehyde as biomarker for oxidative stress: reference interval and effects of lifestyle factors. Clinical Chemistry.43(7): 1209-1214.

[28] Forbes K, MA Webb, I Sehgal. Growth factor regulation of secreted matrix metalloproteinase and plasminogen activators in prostate cancer cells, normal prostate fibroblasts and normal osteoblasts. Prostate cancer and Prostatic Diseases, (2003); 6:148-153.

[29] Friedenreich CM, HK Neilson, BM Lynch. State of the epidemiological evidence on physical activity and cancer prevention. European journal of cancer, (2010); 46(14): 25932604.

[30] Gallagher RP, N Fleshner. Prostate Cancer: Individual risk factors. CMAJ, (1998); 159(7): 807-813.

[31] Goel T, SN Sankhwar Comparative study of zinc levels in benign and malignant lesions of the prostate. Scand J Urol. Nephrol, (2006); 40(2): 108-112.

[32] Gough PJ, DR Greaves, S Gordon. A naturally occurring isoform of the human macrophage scavenger receptor (SR-A) gene generated by alternative splicing blocks modified LDL uptake. J Lipid Res, (1998). 39: 531-543.

[33] Graichen R, D Liu, Y Sun, KO Lee, PE Lobie. Autocrine human growth hormone inhibits placental transforming growth factor-beta gene transcription to prevent apoptosis and allow cell cycle progression of human mammary carcinoma cells. J BiolChem, (2002); 277: 26662-26672.

[34] Inoue K, JW Slaton, BY Eve. Interleukin 8 expression regulates tumorigenicity and metastases in androgen-independent prostate 
cancer. Clin Cancer Res, (2000); 6(5):2104-2119.

[35] Gsur A, E Feik, S Madersbacher. Genetic polymorphisms and prostate cancer risk. World J Urol, (2004); 21:414-423.

[36] Guven M, B Ozturk, ASayal, A Ozeturk, T Ulutin. Lipid peroxidation and antioxidant system in the blood of cancerous patients with metastasis. Cancer Biochem. Biophys, (1999); 17: 155-162.

[37] Halliwell B. Lipid peroxidation, antioxidants and cardiovascular disease: how should we move forward? Cardiovasc. Res, (2000); 47: 410-418.
[38] Hoffman RM, FD Gilliland , JW Eley, LC Harlan, RA Stephenson, JL Stanford, PC Albertson, AS Hamilton, WC Hunt and AL Potosky. Racial and ethnic differences in advanced-stage prostate cancer: the Prostate Cancer Outcomes Study. J. Natl. Cancer Inst. (2001); 93(5): 388-95.

[39] Hughes C, A Murphy, C Martin, Sheils O and J O'Leary. Molecular pathology of prostate cancer. J Clin Pathol, (2005); 58:673-684. 